\title{
Does preemptive gabapentin modulate cytokine response in total knee arthroplasty? A placebo controlled study
}

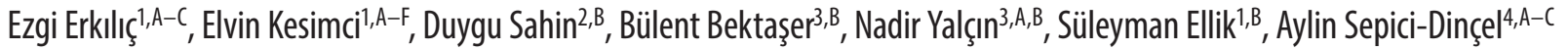 \\ ${ }^{1}$ Clinic of Anesthesiology and Reanimation, Atatürk Training and Research Hospital, Ankara, Turkey \\ ${ }^{2}$ Department of Biochemistry, Faculty of Medicine, Baskent University, Ankara, Turkey \\ ${ }^{3}$ Department of Orthopedics and Traumatology, Atatürk Training and Research Hospital, Ankara, Turkey \\ ${ }^{4}$ Department of Medical Biochemistry, Faculty of Medicine, Gazi University, Ankara, Turkey \\ A - research concept and design; $\mathrm{B}$ - collection and/or assembly of data; $\mathrm{C}$ - data analysis and interpretation; \\ $D$ - writing the article; $E$ - critical revision of the article; $F$ - final approval of the article
}

Address for correspondence

Elvin Kesimci

E-mail: elvinku@yahoo.com

\section{Funding sources}

None declared

\section{Conflict of interest}

None declared

Received on September 19, 2016

Reviewed on October 25, 2016

Accepted on January 24, 2017

\begin{abstract}
Background. Gabapentin, as a structural analogue of $\gamma$-aminobutyric acid, has been investigated to provide pain relief in the early postoperative period following various surgical interventions.

Objectives. The objective of this study was to investigate whether preemptive oral administration of gabapentin $800 \mathrm{mg}$ can reduce postoperative pain and modulate the inflammatory cytokine response in comparison to placebo in patients undergoing total knee arthroplasty under general anesthesia.

Material and methods. Fifty-two patients were randomly divided into 2 groups before surgery, either to receive peroral gabapentin $800 \mathrm{mg}$ or placebo drug, $1 \mathrm{~h}$ before surgery. All patients had general anesthesia with endotracheal intubation, in a standardized fashion, by the same anesthetist. Thirty min before completion of surgery, intramuscular diclofenac sodium $75 \mathrm{mg}$ was administered. Following extubation, visual analogue pain scale (VAS) scores and additional analgesic requirements were recorded at $15 \mathrm{~min}$ at post-anesthesia care unit (PACU), and at $4^{\text {th }}$ and $24^{\text {th }}$ h postoperatively. Plasma levels of interleukin 6 (IL-6), and tumor necrosis factor $R$ (TNF-R) were measured at predetermined time points ( $\mathrm{T}_{0} 1 \mathrm{~h}$ before administration of gabapentin, $\mathrm{T}_{1}$ at postoperative the $4^{\text {th }} \mathrm{h}$ mark, and $\mathrm{T}_{2}$ at postoperative at the $24^{\text {th }} \mathrm{h}$ mark).
\end{abstract}

Results. The VAS scores at postoperative $4^{\text {th }} \mathrm{h}$ were significantly higher in placebo and gabapentin groups compared with VAS scores at PACU and at $24^{\text {th }} h$. The groups did not differ in terms of additional analgesic requirements. In gabapentin group, IL-6 levels at $T_{1}$ and $T_{2}$ were significantly lower in comparison to values measured in placebo group at the same time points. This difference was not significant in TNF-R levels between the groups.

Conclusions. Though preemptive oral gabapentin administration did not reduce postoperative pain and analgesic requirements in total knee arthroplasty surgery, it attenuated IL-6 production on the first postoperative day.

Key words: preemptive, gabapentin, postoperative analgesia, serum IL-6, serum TNF

DOI

$10.17219 /$ acem $/ 68630$

Copyright

Copyright by Author(s)

This is an article distributed under the terms of the

Creative Commons Attribution Non-Commercial License

(http://creativecommons.org/licenses/by-nc-nd/4.0/) 


\section{Introduction}

Osteoarthritis is the most commonly observed joint disorder affecting individuals aged 65 years and older. In these patients, total knee arthroplasty (TKA) is recommended due to joint destruction that results in severe daily pain. Although TKA is performed due to pain and the limitation of movement, joint replacement surgery itself is associated with significant postoperative pain that is also accompanied by increased levels of proinflammatory cytokines, leading to delay in postoperative rehabilitation and discharge from hospital. ${ }^{1}$ Consequently, strategies intended for the modulation of perioperative inflammatory response have great clinical significance for functional recovery. ${ }^{2}$ Recent studies suggest that surgical damage is correlated mainly with serum IL-6 levels as a sensitive indicator of the degree of surgical stress. ${ }^{3}$ It has also been reported to be significantly increased with postoperative complications and mortality. ${ }^{4}$ On the other hand, sufficient postoperative analgesia has been reported to decelerate proinflammatory activation by inhibiting the migration of cytokines and accelerating wound healing. ${ }^{5}$

Gabapentin, as a structural analogue of $\gamma$-aminobutyric acid, has been investigated to provide pain relief in the early postoperative period following various surgical interventions. ${ }^{6}$ It has been reported to reduce pain and opioid consumption in the first $48 \mathrm{~h}$ following anterior cruciate ligament repair. ${ }^{7}$ However, there is no clear data as to whether, in addition to its analgesic effects, gabapentin has an effect on acute phase response.

The aim of the present study was to evaluate the effects of a single dose of oral gabapentin $(800 \mathrm{mg}$ ) administered before total knee arthroplasty, in preventing postoperative pain and reducing the effects of surgery on IL- 6 and TNF-R.

The clinical study's registration was received from the Ethics Committee of Turgut Özal University Medical Faculty (No 08.11.2013/26-99950669/1135).

\section{Material and methods}

A total of 52 patients with American Society of Anesthesiologists physical status I-II (ASA I-II), who were to undergo elective total knee arthroplasty, were informed about the procedure and included in a prospective, randomized, double-blind, placebo-controlled study, and the approval from the Ethics Committee of Turgut Özal University Faculty of Medicine was obtained. The patients with drug or alcohol abuse, allergy to the study drug or non-steroid anti-inflammatory medications, patients with cardiac, respiratory, hepatic, and renal failure, patients with a history of peptic ulcer, and patients that had received steroids in the previous 7 days were excluded. During the preoperative visit, a $10-\mathrm{cm}$ long visual analogue scale (VAS) was given to the patients $(0=$ no pain, $10=$ intolerable pain). The patients were randomly divided into 2 groups before surgery, and another investigator administered peroral gabapentin (Neurontin ${ }^{\circledR}$ ) (Pfizer, Istanbul, Turkey) $800 \mathrm{mg}$ (group G) or saccharine (placebo) (group P) resembling the study drug $30 \mathrm{~min}$ before surgery. Following their arrival in the operating room, the patients underwent standard ASA monitorization (ECG, $\mathrm{SpO}_{2}$, non-invasive blood pressure measurement), and a $20 \mathrm{G}$ intravenous cannula was inserted on the dorsum of the hand to commence saline infusion at a rate of $5 \mathrm{~mL} \cdot \mathrm{kg}^{-1} \cdot \mathrm{h}^{-1}$. Following preoxygenation, anesthesia was induced using propofol $2 \mathrm{mg} \cdot \mathrm{kg}^{-1}$ and remifentanil $1 \mu \mathrm{g} \cdot \mathrm{kg}^{-1}$ administered as intravenous (iv.) bolus. After the administration of rocuronium bromide $0.6 \mathrm{mg} \cdot \mathrm{kg}^{-1}$, the patients were intubated using an endotracheal tube of an appropriate size. The anesthesia was maintained with sevoflurane $1-2 \%, 50 \%$ oxygen and $50 \% \mathrm{~N}_{2} \mathrm{O}$ using controlled ventilation. Remifentanil infusion was continued at a rate of $0.25 \mu \mathrm{g} \cdot \mathrm{kg}^{-1} \cdot \mathrm{min}^{-1}$ during surgery. Remifentanil infusion rate was kept constant during surgery and sevoflurane concentration was titrated between 1 and $2 \%$ to maintain a mean arterial pressure (MAP) of $60-80 \mathrm{~mm} \mathrm{Hg}$. The administration of beta-blocker (bolus, iv.) was scheduled when the measured values were above target mean arterial pressure (MAP). Bradycardia was defined as a heart rate $<50$ beats per minute ( $\mathrm{bpm}$ ), and the administration of atropine was planned for treatment. Decreasing sevoflurane concentration and, should this fail, increasing fluid administration, were planned when MAP was below the target value.

All the patients were administered intramuscular diclofenac sodium $75 \mathrm{mg}$ (Dikloron ${ }^{\circledR} 75 \mathrm{mg} \cdot 3 \mathrm{~mL}^{-1}$, Deva, Istanbul, Turkey) 30 min before the completion of surgery. The inhalation agent and remifentanil infusion were stopped with the cessation of surgery. The neuromuscular block was reversed with the administration of iv. neostigmine $0.04 \mathrm{mg} \cdot \mathrm{kg}^{-1}$ and atropine $0.02 \mathrm{mg} \cdot \mathrm{kg}^{-1}$, and the patients were extubated. The Modified Aldrete Recovery Score was used as the criteria for the transfer of patients from the operating room to the post-anesthesia care unit (PACU) and in the follow-up of recovery. The patients with a Modified Aldrete Recovery Score $\geq 8$ were transferred to the PACU from the operating room. The time to the first analgesic requirement was recorded. Another investigator, who was kept blind to the study protocol, repeated the pain assessment using visual analog scale (VAS) at $15 \mathrm{~min}$ in PACU, and at the $4^{\text {th }}$ and $24^{\text {th }} \mathrm{h}$ marks. When the VAS pain score was $>4$, iv., tramadol $50 \mathrm{mg}$ (Contramal ${ }^{\circledR} 100 \mathrm{mg}$ ) (Abdi İbrahim İlaç Sanayi ve Ticaret A.Ş. Istanbul, Turkey) was administered as iv. bolus. Any possible side effects (nausea, vomiting, respiratory depression) were evaluated.

Blood samples were obtained at predetermined time points for the measurement of serum TNF-R (sTNF-R) and IL-6 ( $\mathrm{T}_{0} 1 \mathrm{~h}$ before oral administration of study drug, $\mathrm{T}_{1}$ at postoperative $4^{\text {th }} \mathrm{h}$ mark, and $\mathrm{T}_{2}$ at postoperative $24^{\text {th }} \mathrm{h}$ mark). The blood samples were stored at $+4^{\circ} \mathrm{C}$ after collection and then sent to the laboratory with a cold chain for the measurement of biochemical parameters. 


\section{Blood sample collection}

Venous blood samples $(5 \mathrm{~mL})$ were obtained from each patient via the antecubital vein $1 \mathrm{~h}$ before gabapentin administration and 4 and $24 \mathrm{~h}$ postoperatively. Blood was collected into a normal $10 \mathrm{~mL}$ Vacutainer ${ }^{\circledR}$ tubes (Becton, Dickinson \& Co., Franklin Lakes, USA). For cytokine measurements, blood samples were centrifuged at $4000 \mathrm{~g}$ for $10 \mathrm{~min}$ at $4^{\circ} \mathrm{C}$ and the plasma was stored at $-80^{\circ} \mathrm{C}$ until analysis. Serum concentrations of IL- 6 and sTNF-R were measured by platinum enzyme-linked immunosorbent assays (ELISA) for quantitative detection (Bender MedSystems GmbH, Campus Vienna Biocenter 2, Vienna, Austria) according to the manufacturer's instructions. Sensitivity was $0.10 \mathrm{ng} / \mathrm{mL}$ for sTNF-R, and $0.92 \mathrm{pg} / \mathrm{mL}$ for IL-6.

\section{Statistical analysis}

The study data was uploaded for analysis to the SPSS (Statistical Package for Social Sciences) for Windows 22.0 (SPSS Inc., Chicago, USA) computer software. Descriptive statistics included mean \pm standard deviation, median (min-max), frequency distribution and percentage. Pearson's $\chi^{2}$ test and Fisher's exact test were used to evaluate the categorical variables. The applicability of the variables to normal distribution was evaluated using visual (histogram and probability graphs) and analytic methods (Shapiro-Wilk test). In case of a significant difference between 2 independent groups, the Student's t-test was used for normally distributed variables. For variables not distributed normally, the Mann-Whitney U test was used to compare 2 independent groups and the Friedman test was used to compare 3 dependent groups. When a significant difference was found between 3 dependent groups, Bonferroni correction was used to determine the source of the significant difference. The relationship between the variables was evaluated using Spearman's correlation coefficient. The level of statistical significance was set at $\mathrm{p}<0.05$.

\section{Results}

In terms of demographic features and surgery time, there was no statistically significant difference between the study patients (Table 1). Intraoperative MAP and heart rate values did not differ between the groups.

There was no statistically significant difference between the groups in terms of VAS scores ( $p>0.05)$; however, VAS scores at the $4^{\text {th }} \mathrm{h}$ mark in group $\mathrm{P}$ and group $\mathrm{G}$ were significantly higher compared with VAS scores measured at PACU and at the $24^{\text {th }} \mathrm{h}$ mark $(\mathrm{p}<0.05)$. The VAS score in group $\mathrm{G}$ at the $24^{\text {th }} \mathrm{h}$ mark was significantly higher than the VAS score at PACU $(\mathrm{p}<0.05)$. The time to the first analgesic requirement was $78.6 \pm 35.2 \mathrm{~min}$ in group $P$ and $87.2 \pm 20.8 \mathrm{~min}$ in group $\mathrm{G}(\mathrm{p}>0.05)$. There was no significant difference between the groups in terms of additional analgesic requirement $(\mathrm{p}>0.05)$.

Serum IL- 6 and sTNF-R values at $\mathrm{T}_{0}$ in both groups were significantly lower compared with the values at $\mathrm{T}_{1}$ and $\mathrm{T}_{2}$. In group $\mathrm{G}$, sTNF-R measured at $\mathrm{T}_{1}$ was significantly lower than measured at $\mathrm{T}_{2}(\mathrm{p}<0.05)$. In group $\mathrm{G}$, serum IL-6 values at $T_{1}$ and $T_{2}$ were significantly lower than the values at the same time points in group $\mathrm{P}(\mathrm{p}=0.048 ; \mathrm{p}=0.024$, respectively). In group $P$, sTNF-R values at $\mathrm{T}_{0}$ were lower than those in group $\mathrm{G}(\mathrm{p}<0.05)$ (Fig. 1, 2).

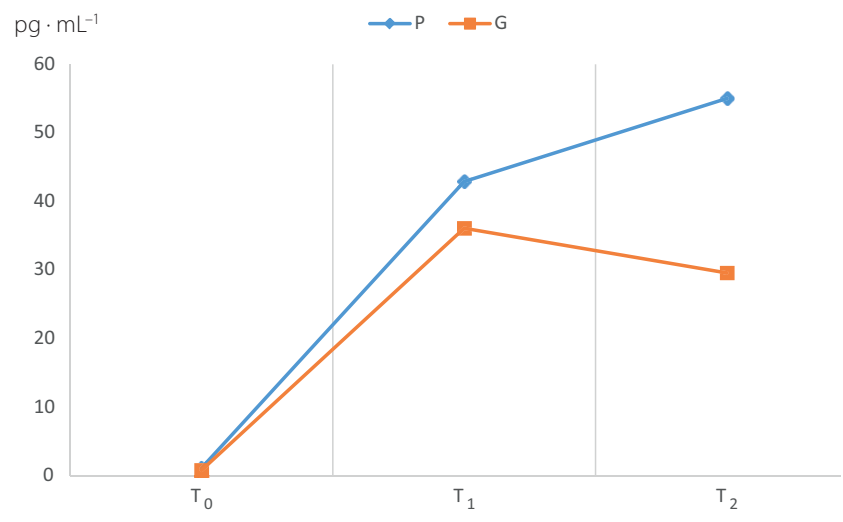

Fig. 1. Changes in serum concentration of IL-6 values

$P$ - group $P ; G$ - group $G ; T_{0}-1$ h before oral administration of study drug; $T_{1}$ - at postoperative $4^{\text {th }} h ; T_{2}$ - at postoperative $24^{\text {th }} \mathrm{h}$.

Table 1. Patients' characteristics, anesthesia and operative data

\begin{tabular}{|c|c|c|c|c|}
\hline \multicolumn{2}{|c|}{ Variables } & $P(n=26)$ & $G(n=26)$ & $p$-value \\
\hline \multicolumn{2}{|l|}{ Age [year] } & $68.65 \pm 6.84$ & $65.54 \pm 8.93$ & $0.164^{\mathrm{a}}$ \\
\hline Gender & $\begin{array}{c}\text { male } \\
\text { female }\end{array}$ & $\begin{array}{c}6(23.1 \%) \\
20(76.9 \%)\end{array}$ & $\begin{array}{c}5(19.2 \%) \\
21(80.8 \%)\end{array}$ & 0.734 \\
\hline \multicolumn{2}{|c|}{$\mathrm{BMI}\left[\mathrm{kg} / \mathrm{m}^{2}\right]$} & $32.39 \pm 5.66$ & $34.07 \pm 5.33$ & $0.278^{a}$ \\
\hline ASA & $\begin{array}{l}\text { I } \\
\|\end{array}$ & $\begin{array}{c}0 \\
26(100 \%)\end{array}$ & $\begin{array}{c}3(11.5 \%) \\
23(88.5 \%)\end{array}$ & $0.235^{b}$ \\
\hline \multicolumn{2}{|c|}{ Anesthesia time [min] } & $108.08 \pm 18.77$ & $113.85 \pm 17.91$ & $0.262^{\mathrm{a}}$ \\
\hline \multicolumn{2}{|c|}{ Operation time [min] } & $95.00 \pm 18.17$ & $102.69 \pm 18.61$ & $0.138^{a}$ \\
\hline
\end{tabular}

Continuous variables were expressed as mean \pm standard deviation and categorical variables were expressed as number (column percentage);

a Student's t-test; ${ }^{b}$ Fisher's exact test ; ASA - American Society of Anesthesiologists physical status; P - placebo group; G - gabapentin group. 


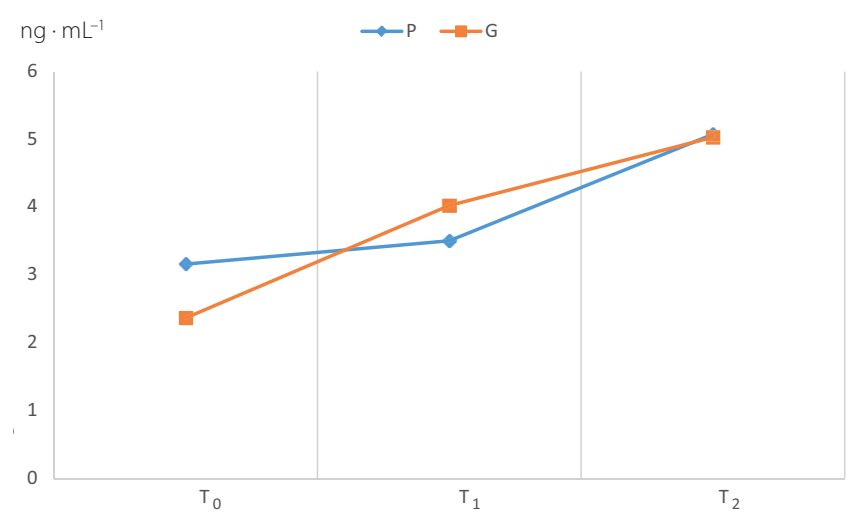

Fig. 2. Changes in serum concentration of TNF-R values

P - group P; G - group $G ; T_{0}-1$ h before oral administration of study drug; $T_{1}-$ at postoperative $4^{\text {th }} h ; T_{2}$ - at postoperative $24^{\text {th }} h$.

\section{Discussion}

The present study showed that preemptive oral gabapentin had no effect on providing postoperative pain relief after TKA, but it significantly attenuated IL-6 levels in the first $24 \mathrm{~h}$ after the postoperative period, most prominently in the early hours following surgery.

The preemptive use of gabapentin in different doses and in different surgical interventions has been studied in terms of decreasing postoperative pain scores and analgesic consumption. ${ }^{8}$ The studies about oral gabapentin differ from each other either by the usage of different doses of gabapentin or the agents to which gabapentin was compared. Yet, there are contradictory reports about the ideal dose of preemptive gabapentin. Bang et al. performed a randomized, double-blind, placebo-controlled study on 46 patients undergoing arthroscopic rotator cuff repair, and evaluated oral gabapentin $300 \mathrm{mg}$ vs placebo. Interestingly, the VAS scores in the gabapentin group $24 \mathrm{~h}$ after the postoperative period were significantly lower than in the control group. ${ }^{9}$ In another study, the authors administered a higher dose of oral gabapentin, such as $1200 \mathrm{mg}, 1 \mathrm{~h}$ before surgery, to evaluate postoperative pain following spinal surgery, and they reported that gabapentin reduced pain scores in the early postoperative period and morphine consumption, monitored by a patient-controlled analgesia (PCA) pump and, therefore, reduced the side effects associated with morphine use. ${ }^{10}$ Similarly, this high dose of preoperative gabapentin administered $1 \mathrm{~h}$ before surgery reduced postoperative morphine consumption after lower extremity orthopedic surgery without affecting pain scores. ${ }^{11}$ The difference in the results of the above studies might be due to the varying doses of gabapentin and dissimilar pain levels in the surgeries. Pandey et al. suggested that $600 \mathrm{mg}$ and higher doses were better without side effects in patients undergoing lumbar discectomy procedure. ${ }^{12}$ Although we used an intermediate dose $(800 \mathrm{mg})$ consistent with the doses studied in the literature, in our study we could not show any benefits of gabapentin over the control group in total knee arthroplasties. Another randomized, double-blind, placebo-controlled study evaluated different doses of oral gabapentin (300 and $600 \mathrm{mg}$ ) vs placebo administered $1 \mathrm{~h}$ before surgery in patients undergoing caesarean section under spinal anesthesia. The evaluation of analgesic consumption at $6^{\text {th }}, 12^{\text {th }}, 24^{\text {th }}$ and $48^{\text {th }} \mathrm{h}$ during the postoperative period revealed that gabapentin had no favorable effects on postoperative outcomes and did not reduce analgesic consumption. ${ }^{13}$ On the contrary, Clarke et al. supported the use of gabapentin in the acute postoperative period, after total knee arthroplasty with different doses of oral gabapentin administered $2 \mathrm{~h}$ before surgery preoperatively and postoperatively more than once and continuing for 4 days. Besides, their patients also received celecoxib $2 \mathrm{~h}$ before surgery. ${ }^{14}$ This study actually could not be compared with our study, because of the multiple use of gabapentin with another analgesic adjunct. As well as these studies, there are also other studies comparing gabapentin's effects with other analgesic agents resulting in contradictory ideas. ${ }^{15}$

It is known that the increased severity of surgery and magnitude of tissue injury are related with increases in the plasma levels of proinflammatory cytokines. $.^{16} \mathrm{TNF}-\alpha$ and IL- 6 are 2 early important features of acute injury that play a role in persistent postoperative pain syndromes. ${ }^{17-19} \mathrm{Li}$ et al. showed a positive correlation between dexmedetomidine administration, VAS scores and plasma TNF- $\alpha$, IL-6 levels, in patients undergoing dental surgery. ${ }^{20}$ This supported the finding that acute inflammation and, thus, inflammatory cytokine release caused postoperative pain, which provided an alternative treatment for inflammatory pain as well. ${ }^{21}$ In another study, gabapentin was seen to play a role in the down-regulation of pro-inflammatory cytokine TNF- $\alpha$, IL-1 $\beta$ and IL- 6 expression and up-regulation of anti-inflammatory cytokine IL-10 expression in the rat spinal cord. ${ }^{22}$ Apart from that, in a rat model of neuropathic pain, antinociception was observed as a result of inhibited expression of the pro-inflammatory cytokines TNF- $\alpha$, IL- $1 \beta$ and IL- 6 by gabapentin. ${ }^{23}$ Unfortunately, we could not find many studies showing a one-to-one correspondence with our study to compare our results. Some other analgesic agents have been tried in this aspect in a few other studies. In one study, Pandazi et al. showed a decrease in serum levels of IL-6 in patients undergoing colorectal surgery, provided by parecoxib administered preincisonally vs postincisionally. ${ }^{24}$ Similarly, Feng et al. observed a reduction in serum IL- 6 levels by preincisional administration of rofecoxib in comparison with placebo. ${ }^{25}$ However, Bao et al. could not show any change in the level of plasma TNF- $\alpha$ with either preincisional or postincisional parecoxib administration after total hip replacement. ${ }^{26}$ This was the same in other studies with other types of surgical procedures. ${ }^{27}$ Only one study showed a significant increase in the postoperative TNF- $\alpha$ levels, but it was in wound and peritoneal fluid supporting TNF- $\alpha$ 's hypersensitivity for mechanical nociception. ${ }^{28}$ 
These examples are mainly about highly selective COX-2 inhibitors. Furthermore, Pirbudak et al. could not show any difference in either the inflammation markers, mainly C-reactive protein, or pain intensity in patients treated with either tramadol or tramadol plus gabapentin after lumbar disc herniation transacted with epidural steroid injection. ${ }^{29}$ However, mainly in animal studies, gabapentin's antihyperalgesic effect in inflammatory pain models had been exerted. ${ }^{30,31}$

Although this paper is limited, as the sample size is small and postoperative analgesic consumption could not be standardized by PCA morphine, we still believe that this trial could be instrumental in demonstrating the importance of splitting the relationship between inflammatory response and acute postoperative pain for the patient's comfort.

In conclusion, the present study found that oral gabapentin administered in the preoperative period $1 \mathrm{~h}$ before surgery had no effect on providing postoperative pain relief after total knee arthroplasty; however, gabapentin significantly decreased IL-6 levels in the first postoperative $24 \mathrm{~h}$, most prominently in the early period.

\section{References}

1. Dighe K, Clarke H, McCartney CJ, Wong CL. Perioperative gabapentin and delirium following total knee arthroplasty: A post-hoc analysis of a double-blind randomized placebo-controlled trial. Can J Anaesth. 2014;61:1136-1137. doi: 10.1007/s12630-014-0235-5

2. Andres BM, Taub DD, Gurkan I, Wenz JF. Postoperative fever after total knee arthroplasty: The role of cytokines. Clin Orthop Relat Res. 2003;415:221-231.

3. Hall GM, Peerbhoy D, Shenkin A, Parker CJ, Salmon P. Relationship of the functional recovery after hip arthroplasty to the neuroendocrine and inflammatory responses. Br J Anaesth. 2001;87:537-542.

4. Szczepanik AM, Scislo L, Scully T, et al. IL-6 serum levels predict postoperative morbidity in gastric cancer patients. Gastric Cancer. 2011;14:266-273. doi: 10.1007/s10120-011-0039-z

5. Giannoudis PV, Hak D, Sanders D, Donohoe E, Tosounidis T, Bahney C. Inflammation, bone-healing, and anti-inflammatory drugs: An update. J Orthop Trauma. 2015;29:S6-9. doi: 10.1097/BOT.000000 0000000465

6. Mathiesen O, Møiniche S, Dahl JB. Gabapentin and postoperative pain: A qualitative and quantitative systematic review, with focus on procedure. BMC Anesthesiol. 2007;7:6. doi: 10.1186/1471-2253-7-6

7. Ménigaux C, Adam F, Guignard B, Sessler DI, Chauvin M. Preoperative gabapentin decreases anxiety and improves early functional recovery from knee surgery. Anesth Analg. 2005;100:1394-1399.

8. Farzi F, Naderi Nabi B, Mirmansouri A, et al. Postoperative pain after abdominal hysterectomy: A randomized, double-blind, controlled trial comparing the effects of tramadol and gabapentin as premedication. Anesth Pain Med. 2016;6:e32360. doi: 10.5812/aapm.32360

9. Bang SR, Yu SK, Kim TH. Can gabapentin help reduce postoperative pain in arthroscopic rotator cuff repair? A prospective, randomized, double-blind study. Arthroscopy. 2010;26:S106-111. doi: 10.1016/j. arthro.2009.11.010

10. Turan A, Karamanlioğlu B, Memiş D, et al. Analgesic effects of gabapentin after spinal surgery. Anesthesiology. 2004;100:935-938.

11. Montazeri K, Kashefi P, Honarmand A. Pre-emptive gabapentin significantly reduces postoperative pain and morphine demand following lower extremity orthopedic surgery. Singapore Med J. 2007;48: 748-751.

12. Pandey CK, Navkar DV, Giri PJ, et al. Evaluation of the optimal preemptive dose of gabapentin for postoperative pain relief after lumbar discectomy: A randomized, double-blind, placebo controlled study. J Neurosurg Anesthesiol. 2005;17:65-68.
13. Short J, Downey K, Bernstein P, Shah V, Carvalho JC. A single preoperative dose of gabapentin does not improve postcesarean delivery pain management: A randomized, double-blind, placebo-controlled dose-finding trial. Anesth Analg. 2012;115:1336-1342. doi: 10.1213/ ANE.0b013e31826ac3b9

14. Clarke H, Pereira S, Kennedy D, et al. Gabapentin decreases morphine consumption and improves functional recovery following total knee arthroplasty. Pain Res Manag. 2009;14:217-222.

15. Secrist ES, Freedman KB, Ciccotti MG, Mazur DW, Hammoud S. Pain management after outpatient anterior cruciate ligament reconstruction: A systematic review of randomized controlled trials. Am J Sports Med. 2015 Dec 18. pii: 0363546515617737.

16. Watt DG, Horgan PG, McMillan DC. Routine clinical markers of the magnitude of the systemic inflammatory response after elective operation: A systematic review. Surgery. 2015;157:362-380. doi: 10. 1016/j.surg.2014.09.009

17. Schäfers M, Geis C, Svensson Cl, Luo ZD, Sommer C. Selective increase of tumor necrosis factor-alpha in injured and spared myelinated primary afferents after chronic constrictive injury of rat sciatic nerve. Eur J Neurosci. 2003;17:791-804.

18. Koch A, Zacharowski K, Boehm O, et al. Nitric oxide and pro-inflammatory cytokines correlate with pain intensity in chronic pain patients. Inflamm Res. 2007;56:32-37.

19. Davies AL, Hayes KC, Dekaban GA. Clinical correlates of elevated serum concentrations of cytokines and autoantibodies in patients with spinal cord injury. Arch Phys Med Rehabil. 2007;88:1384-1393.

20. Li S, Yang Y, Yu C, et al. Dexmedetomidine analgesia effects in patients undergoing dental implant surgery and its impact on postoperative inflammatory and oxidative stress. Oxid Med Cell Longev. 2015;2015:186736. doi: 10.1155/2015/186736

21. Thomas B, Farquhar-Smith P. Extended-release gabapentin in postherpetic neuralgia. Expert Opin Pharmacother. 2011;12:2565-2571. doi: 10.1517/14656566.2011.622267

22. Bao YH, Zhou QH, Chen R, et al. Gabapentin enhances the morphine anti-nociceptive effect in neuropathic pain via the interleukin-10-heme oxygenase-1 signalling pathway in rats. JMol Neurosci. 2014;54:137-146. doi: 10.1007/s12031-014-0262-2

23. Lee BS, Jun IG, Kim SH, Park JY. Intrathecal gabapentin increases interleukin-10 expression and inhibits pro-inflammatory cytokine in a rat model of neuropathic pain. J Korean Med Sci. 2013;28:308-314. doi: 10.3346/jkms.2013.28.2.308

24. Pandazi A, Kapota E, Matsota P, Paraskevopoulou P, Dervenis C, Kostopanagiotou G. Preincisional versus postincisional administration of parecoxib in colorectal surgery: Effect on postoperative pain control and cytokine response. A randomized clinical trial. World J Surg. 2010;34:2463-2469.

25. Feng Y, Ju H, Yang B, An H. Effects of a selective cyclooxygenase-2 inhibitor on postoperative inflammatory reaction and pain after total knee replacement. J Pain. 2008;9:45-52.

26. Bao Y, Fang J, Peng L, et al. Comparison of preincisional and postincisional parecoxib administration on postoperative pain control and cytokine response after total hip replacement. J Int Med Res. 2012;40:1804-1811.

27. Catena F, Ansaloni L, Avanzolini A, Di Saverio S, D'Alessandro L, Maldini Casadei M. Systemic cytokine response after emergency and elective surgery for colorectal carcinoma. Int J Colorectal Dis. 2009;24:803-808.

28. Sachs D, Cunha FQ, Poole S, Ferreira SH. Tumour necrosis factor- $a$, interleukin- $1 \beta$ and interleukin- 8 induce persistent mechanical nociceptor hypersensitivity. Pain. 2002;96:89-97.

29. Pirbudak L, Ciçek H, Işik M, Zer Y. The effect of tramadol and tramadol + gabapentin combination in patients with lumbar disc herniation after epidural steroid injection. Turk JMed Sci. 2015;45:1214-1219.

30. Lu Y, Westlund KN. Gabapentin attenuates nociceptive behaviors in an acute arthritis model in rats. J Pharmacol Exp Ther. 1999;290: 214-219.

31. Field MJ, Holloman EF, McCleary S, Hughes J, Singh L. Evaluation of gabapentin and S-(+)-3-isobutylgaba in a rat model of postoperative pain. J Pharmacol Exp Ther. 1997;282:1242-1246. 